\title{
Osteoporosis in COPD: Are Bones Brittle in COPD?
}

\author{
Shabir Ahmad Bhat, Mohamad Muzzafer Mir* and Parvaiz A Koul
}

Sher-I-Kashmir Institute of Medical Sciences, Srinagar, Jammu and Kashmir, India

\begin{abstract}
Chronic obstructive pulmonary disease COPD is a systemic disease with predominant respiratory symptoms. Airflow obstruction has significant effects on cardiac function and gas exchange with systemic consequences. Various extra pulmonary effects include, Skeletal muscle wasting and cachexia, ischemic heart disease, heart failure including left sided heart failure, osteoporosis, Normocytic anemia, lung cancer, depression etc. Osteoporosis becomes more prevalent in COPD patients as the disease progresses. Present study is a case-control study that was conducted by department of Internal and pulmonary medicine. Patients diagnosed with COPD based on ATS guidelines and staged based on GOLD guidelines that were following as an outpatient in pulmonary clinic of SKIMS were selected for the study. Total of sixty patients of COPD were taken and were compared with one hundred twenty age and sex matched controls. In current study we found no significant correlation between osteoporosis and smoking, although smoking is clearly a risk factor for both osteoporosis and COPD.
\end{abstract}

Keywords: Osteoporosis; Chronic obstructive pulmonary disease; Smoking

\section{Introduction}

Chronic obstructive pulmonary disease COPD is a systemic disease with predominant respiratory symptoms. Airflow obstruction has significant effects on cardiac function and gas exchange with systemic consequences. A part from respiratory symptoms COPD is associated with number of extra pulmonary effects, which are as a direct result of various systemic inflammatory markers or worsening of the underlying comorbid conditions [1,2]. Various extra pulmonary effects include, Skeletal muscle wasting and cachexia [3,4], ischemic heart disease $[3,5]$ heart failure including left sided heart failure [6], osteoporosis [7], Normocytic anaemia [8], lung cancer, depression [9] etc.

Comorbid diseases potentiate the morbidity of COPD, leading to increased hospitalizations, mortality and healthcare costs [10]. Therefore comorbid conditions complicate the management of COPD and needs to be recognized early and managed.

Osteoporosis becomes more prevalent in COPD patients as the disease progresses [11]. Increase prevalence of osteoporosis in COPD patients can be explained based on the presence of various risk factors which are known to predispose osteoporosis like low body mass index, immobility due to decrease muscle mass and respiratory dysfunction, smoking, hypogonadisim steroid either systemic or inhalational [12].

Osteoporosis leads to an increased susceptibility to fractures, especially at hip, wrist, and the thoracic and lumbar spine, causing significant morbidity to the patient, such as pain, disabilities, decreased mobility, and impaired respiratory function [13] and in even death. Therefore, an early treatment of osteoporosis seems reasonable to consider. This treatment should consist of lifestyle advises (e.g. physical weight baring physical exercise, smoking cessation, use of dairy products) and pharmacological treatment. Prevalence of osteoporosis in COPD has been reported with variable frequency by different investigators, depending on the diagnostic methods used, the population studied, and the severity of the underlying respiratory disease. Overall, a higher prevalence of osteoporosis is generally found in patients with COPD when compared with healthy control subjects. A comparison study by Parthasarathi et al. [14] is the only available study from India in which thirty seven COPD patients (all belonging to GOLD III/IV category) were studied for osteoporosis by using broadband ultrasound densitometer. He quotes an incidence of about $21 \%$ of osteoporosis in his patients
The present study has aimed at estimating the prevalence of osteoporosis in COPD patients in our population.

\section{Patients and Methods}

Present study is a case- control study that was conducted by department of Internal and pulmonary medicine. Patients diagnosed with COPD based on ATS [15] guidelines and staged based on GOLD guidelines that were following as an outpatient in pulmonary clinic of SKIMS were selected for the study. Only those cases of COPD were enrolled in the study, who gave consent for DEXA scan and those who had no normalization due to either spontaneous variability or treatment. Patients who were on long term oral steroids and/or diseases that significantly predisposes to osteoporosis were excluded from the study.

Total of sixty patients of COPD were taken and were compared with one hundred twenty age and sex matched controls. All Patients underwent BMD that was estimated by dual energy absorptiometry in the lumbar spine (L2 and L4), femoral neck and whole body. WHO criteria for definition of osteoporosis was applied and patients with T-score of $>-2.5$ SD were diagnosed to have osteoporosis, -1 SD to -2.5 SD were diagnosed to have osteopenia and $<-1$ SD as normal.

Complete medical history including past and present medications (especially steroids), smoking history, were included. Other parameters observed were body weight, height, body mass index BMI, which was defined as low $\left(<18 \mathrm{~kg} / \mathrm{m}^{2}\right)$, normal $\left(18-25 \mathrm{~kg} / \mathrm{m}^{2}\right)$, overweight $(25$ $\left.30 \mathrm{~kg} / \mathrm{m}^{2}\right)$ and obese $\left(>30 \mathrm{~kg} / \mathrm{m}^{2}\right)$. Basic laboratory parameters were analyzed in order to exclude other causes of osteoporosis.

Statistical analysis was performed by using SPSS statistical software package version 17 . Continuous data was analyzed using analysis of variance and two sample independent $\mathrm{t}$-tests. Multinomial regression

${ }^{*}$ Corresponding author: Muzzafer Mohamad Mir, Sher-I-Kashmir Institute of Medical Sciences, Srinagar, Jammu and Kashmir, India, Tel: 919419033817 . E-mail: drmuzzafer@yahoo.co.in

Received September 21, 2017; Accepted August 03, 2017; Published August 07, 2017

Citation: Bhat SA, Mir MM, Koul PA (2017) Osteoporosis in COPD: Are Bones Brittle in COPD? J Pulm Respir Med 7: 417. doi: 10.4172/2161-105X.1000417

Copyright: ( 2017 Bhat SA, et al. This is an open-access article distributed under the terms of the Creative Commons Attribution License, which permits unrestricted use, distribution, and reproduction in any medium, provided the original author and source are credited. 
and categorical data was analyzed by using Chi-square and Fishers exact test. P-value less than 0.005 were considered to be statistically significant. Risk factors for osteoporosis were identified by univariate and multivariate logistic regression analysis.

\section{Results}

Comparing the results of bone mass density at different sites among cases and controls in our study, showed that COPD patients had lower BMD at all sites as compared to controls. However statistically significant difference was seen only at left and right femur neck (both p-value 0.001) (Table 1).

It was also observed that with increase in severity of COPD percentage of cases with osteoporosis increased and reached statistically significant levels at whole body and at right femur (Table 2).

There was a significant correlation between BMI and prevalence of osteoporosis in our series. Cases with lower body mass index had higher prevalence of osteoporosis as compared to cases with higher body mass index.

Using Univariate multinomial regression analysis with osteopenia and osteoporosis at all sites as the dependent variables and age, sex, BMI, fat free mass (FFM), smoking, corticosteroid use, and stage of COPD as co-variables, We found that with respect to whole body, only $\mathrm{BMI}$ had significant correlation for both osteopenia ( $\mathrm{p}$-value 0.033 ) and osteoporosis (p-value 0.013 ).

We also observed that increasing age, decrease in BMI, FFM, and increased COPD stage independently increased the risk of osteoporosis and osteopenia.

\section{Discussion}

Prevalence of osteoporosis in COPD has been reported with variable frequency by different investigators, depending on the diagnostic methods used, the population studied, and the severity of the underlying respiratory disease [16]. It varies from $4 \%$ [16] to $69 \%$ [17] in different studies.

The present study revealed osteoporosis in $65 \%$ of patients of COPD when bone density at lumbar spine was taken into consideration and $27 \%$ when whole body bone density was considered, it was $31 \%$ and $35 \%$ once density at left femur and right femur respectively was taken into consideration. Thus a site specific difference in osteoporosis was found in patients of COPD in the present study. This difference in results could be explained by means of racial differences affecting the BMD at various skeletal sites, as observed by [18] almost similar results as were observed by Tschopp et al. [17], Incalzi et al. [19] and Jorgenson et al. [20] in their studies.

There was a significant difference in osteoporosis between cases of COPD (60 cases/120 controls) and controls at all sites in our series, these observations were in consistent with results observed by Roogbeh et al. [21] (50 cases/50 controls) and Bolton et al. [22] (81 cases/38 controls). Our study included twice the number of controls as compared to patients which is an important strength in establishing the correlation between COPD and osteoporosis.

Cases of COPD had lower bone mineral density at all sites as compared to controls in our series, reaching statistically significant only at femur $(\mathrm{p}=0.001)$. Similar results were observed by Bolton et al. in his study [22] (Table 3).

COPD patients have several risk factors that might contribute to development of osteoporosis, including smoking, low body mass index, use of steroids both systemic and inhalational, increasing severity of COPD. In our series we observed that increasing age, decrease in BMI, FFM, and increased stage of COPD independently increased the risk of osteopenia and osteoporosis.

By using Univariate multinomial regression analysis with osteopenia and osteoporosis at all sites as dependent variables and age, sex, BMI, FFM, smoking, use of steroids and stage of COPD as co-variables, only BMI has a significant correlation for osteopenia and osteoporosis when whole body BMD was taken into consideration. This observation was also made in a study conducted by Verboom et al. [23] in osteoporotic COPD patients.

Comparing other variables, we found that at L/S spine, FFM significantly correlated both with osteopenia ( $p$-value $=0.050)$ and osteoporosis (p-value 0.026). At the left femur, FFM and stage of COPD had a significant correlation with osteopenia. Whereas osteoporosis in right femur correlates significantly with age, BMI, FFM and stage of

\begin{tabular}{|c|c|c|c|c|c|c|}
\hline \multirow[b]{2}{*}{ Site } & \multicolumn{2}{|c|}{ Osteoporosis } & \multirow[t]{2}{*}{$P$ value } & \multicolumn{2}{|c|}{ Osteopenia } & \multirow[t]{2}{*}{$P$ value } \\
\hline & Cases (\%) & Control (\%) & & Cases (\%) & Control (\%) & \\
\hline Total body & 36 & 7.5 & $0.001^{*}$ & 28 & 67 & $<0.0001^{*}$ \\
\hline LS spine & 65 & 29.1 & $0.001^{*}$ & 22.3 & 33.3 & 0.12 \\
\hline Left femur & 31 & 15.8 & $0.014^{*}$ & 50 & 30 & $0.013^{*}$ \\
\hline Right femur & 35 & 5 & $0.001^{*}$ & 45 & 30.8 & 0.07 \\
\hline
\end{tabular}

Table 1: Prevalence of osteoporosis among cases and controls in the study.

\begin{tabular}{|c|c|c|}
\hline BMD at different sites & Cases $(\mathbf{n = 6 0 )}$ & Controls (n=120) \\
\hline Total Body & $1.03 \pm 0.228$ & $1.038 \pm 0.208$ \\
\hline L/S Spine & $0.853 \pm 0.222$ & 0.83 \\
\hline Left Femur & $0.800 \pm 0.176$ & 0.34 \\
\hline Right Femur & $0.7784 \pm 0.169$ & 0.364 \\
\hline
\end{tabular}

Table 2: Bone mineral density at different sites in COPD patients.

\begin{tabular}{|c|c|c|c|c|c|}
\hline & Total Group (n=60) & GOLD 1 (n=6) & GOLD II (n=22) & GOLD III (n=21) & GOLD IV (n=11) \\
\hline Total Body (\%) & 26.6 & 6.3 & 12.5 & 62.5 & 18.8 \\
\hline L/S Spine (\%) & 65.5 & 5.1 & 30.8 & 43.6 & 20.5 \\
\hline Left Femur (\%) & 31.1 & 0 & 26.3 & 47.4 & 0.094 \\
\hline Right femur (\%) & 35 & 0 & 23.8 & 52.4 & 26.3 \\
\hline
\end{tabular}

Table 3: Prediction of osteoporosis in COPD patients belonging to different GOLD categories. 
Citation: Bhat SA, Mir MM, Koul PA (2017) Osteoporosis in COPD: Are Bones Brittle in COPD? J Pulm Respir Med 7: 417. doi: 10.4172/2161105X.1000417

Page 3 of 4

\begin{tabular}{|c|c|c|c|c|c|c|c|c|}
\hline \multirow[t]{2}{*}{ Variables } & \multicolumn{4}{|c|}{ Osteopenia } & \multicolumn{4}{|c|}{ Osteoporosis } \\
\hline & OR & $95 \%$ & $\mathrm{Cl}$ & $P$ value & OR & $95 \%$ & $\mathrm{Cl}$ & $P$ value \\
\hline Age & 0.911 & 0.794 & 1.044 & 0.179 & 0.994 & 0.852 & 1.161 & 0.943 \\
\hline $\mathrm{BMI}$ & 0.743 & 0.566 & 0.977 & $0.033^{*}$ & 0.618 & 0.423 & 0.902 & $0.013^{*}$ \\
\hline $\mathrm{FEV}_{1}$ & 1.086 & 0.93 & 1.269 & 0.298 & 1.094 & 0.906 & 1.32 & 0.352 \\
\hline FFM & 1 & 0.999 & 1.001 & 0.814 & 0.999 & 0.998 & 1.001 & 0.405 \\
\hline Male & 2.251 & 0.276 & 18.351 & 0.448 & 1.108 & 0.112 & 11.003 & 0.93 \\
\hline Smoking & 2.109 & 0.129 & 34.474 & 0.601 & 2.857 & 0.14 & 58.23 & 0.495 \\
\hline Steroid use & 2.812 & 0.283 & 27.966 & 0.378 & 3.708 & 0.252 & 54.468 & 0.339 \\
\hline GOLD I & 0.0813 & 8.599 & 8.599 & - & 0.009 & 0.0039 & 9.969 & 0.123 \\
\hline GOLD II & 0.043 & 7.439 & 24.847 & 0.332 & 0.017 & 0.00185 & 27.479 & 0.281 \\
\hline GOLDIII & 0.115 & 0.002 & 7.251 & 0.307 & 0.347 & 0.003 & 34.998 & 0.653 \\
\hline
\end{tabular}

Table 4: Effect of different variable on COPD patients for developing Osteopenia and Osteoporosis.

COPD. The disparity between these sites may be because of chance only or other mechanisms which might have to be explored further.

In our study we found a significant correlation between decrease in BMI and increased prevalence of osteoporosis. The finding that a decreasing BMI is associated with an increasing risk of osteoporosis is in line with several other studies in COPD patients [23-24]. Bolton and colleagues found the highest prevalence of osteoporosis (50\%) and osteopenia (50\%) in cachectic COPD patients (Table 4). The link between low BMI and osteoporosis in COPD patients is not entirely clear yet. It might be due to decreased physical activity, increased inflammation, or other mechanisms leading to proteolysis [25-26].

FFM was an important determinant of osteoporosis in our study. In current study we also observed that a higher GOLD stage and /or low FEVI were an important predictor of osteoporosis. This observation was also demonstrated by Vrieze et al. [27]. In COPD patients, systemic inflammation can be a key factor, as reduced lung function has been found to be associated with increased inflammatory markers, which is a risk factor for osteoporosis [28].

In the current study we did not find any significant influence of use of corticosteroid on the risk of osteoporosis. In this respect our study was limited by the non availability of valid information regarding length of treatment. In addition, the number of courses and the cumulative dose were unknown, and different corticosteroid regimens had different effects on BMD. Further (longitudinal) research regarding these potential confounders of osteoporosis in COPD patients is needed.

\section{Conclusion}

In current study we found no significant correlation between osteoporosis and smoking, although smoking is clearly a risk factor for both osteoporosis and COPD. In the current study we collected information on the patient's number of pack years, but we could not detect any difference in smoking habits between osteoporotic patients and non-osteoporotic patients. This does not indicate that smoking is not a risk factor for osteoporosis, it is just we could not demonstrate it in our study. But it might also suggest that some people do not develop osteoporosis with smoking because of either yet unidentified genetic component or influence of environmental factors which might outweigh the effects of smoking on bone mass.

\section{References}

1. Agusti AG, Noguera A, Sauleda J, Sala E, Pons J, et al. (2003) Systemic effects of chronic obstructive pulmonary disease. Eur Respir J 21: 347-360.

2. Gan WQ, Man SF, Senthilselvan A, Sin DD (2004) Association between chronic obstructive pulmonary disease and systemic inflammation: a systematic review and a metaanalysis. Thorax 59: 574-580.

3. Agusti A, Soriano JB (2008) COPD as a systemic disease. COPD 5: 133-138.
4. Hopkinson NS, Tennant RC, Dayer MJ, Swallow EB, Hansel TT, et al. (2007) A prospective study of decline in fat free mass and skeletal muscle strength in chronic obstructive pulmonary disease. Respir Res 8: 25.

5. Sin DD, Wu L, Man SF (2005) The relationship between reduced lung function and cardiovascular mortality: A population-based study and a systematic review of the literature. Chest 127: 1952-1959.

6. Rutten FH, Cramer MJ, Lammers JW, Grobbee DE, Hoes AW (2006) Heart failure and chronic obstructive pulmonary disease: An ignored combination? Eur J Heart Fail 8: 706-711.

7. Jorgensen NR, Schwarz P (2008) Osteoporosis in chronic obstructive pulmonary disease patients. Curr Opin Pulm Med 14: 122-127.

8. John M, Hoernig S, Doehner W, Okonko DD, Witt C, et al. (2005) Anemia and inflammation in COPD. Chest 127: 825-829.

9. Yohannes AM, Baldwin RC, Connolly MJ (2006) Depression and anxiety in elderly patients with chronic obstructive pulmonary disease. Age Ageing 35: 457-459.

10. Mannino DM, Thorn D, Swensen A, Holguin F (2008) Prevalence and outcomes of diabetes, hypertension, and cardiovascular disease in chronic obstructive pulmonary disease. Eur Respir J 32: 962-969.

11. Leech JA, Dulberg C, Kellie S, Pattee L, Gay J (1990) Relationship of lung function to severity of osteoporosis in women. Am Rev Respir Dis 141: 68-71.

12. Dubois EF, Roder E, Dekhuijzen PN, Zwinderman AE, Schweitzer DH (2002) Dual energy $\mathrm{X}$-ray absorptiometry outcomes in male COPD patients after treatment with different glucocorticoid regimens. Chest 121: 1456-1463.

13. Bhattacharyya P, Paul R, Ghosh M, Dey R, Dey R, et al. (2011) Prevalence of osteoporosis and osteopenia in advanced chronic obstructive pulmonary disease patients. Lung India 28: 184-186.

14. American Thoracic Society and European Respiratory Society (2004) COPD Guidelines. Standards for the diagnosis and treatment.

15. Lehouck A, Boonen S, Decramer M, Janssens W (2011) COPD, Bone Metabolism, and Osteoporosis. Chest 139: 648-657.

16. Tschopp O, Boehler A, Speich R, Weder W, Seifert B, et al. (2002) Osteoporosis before lung transplantation: association with low body mass index, but not with underlying disease. Am J Transplant 2: 167-172.

17. Wu XP, Liao EV, Huang G, Dai RC, Zhang H (2003) A comparison study of the reference curves of bone mineral density at different skeletal sites in native Chinese, Japanese, and American Caucasian women. Calcif Tissue Int 73 : 122-132.

18. Incalzi RA, Caradonna P, Ranieri P, Basso S, Fuso L, et al. (2000) Correlates of osteoporosis in chronic obstructive pulmonary disease. Respir Med 94: 10791084

19. Jørgensen NR, Schwarz P, Holme I, Henriksen BM, Petersen LJ, et al (2007) The prevalence ofOsteoporosis in patients with chronic obstructive pulmonaryDisease: a cross sectional study. Respir Med 101: 177-185.

20. Roogbeh N, Ali J, Syed AJM, Adeli SH, Heydari A (2004) Comparison of osteoporosis between male smokers with and without COPD. Tanaffos 3: 13-18.

21. Bolton CE, Ionescu AA, Shiels KM, Pettit RJ, Edwards PH, et al. (2004 
Citation: Bhat SA, Mir MM, Koul PA (2017) Osteoporosis in COPD: Are Bones Brittle in COPD? J Pulm Respir Med 7: 417. doi: 10.4172/2161105X.1000417

Associated loss of fat-free mass and bone mineral density in chronic obstructive pulmonary disease. Am J Respir Crit Care Med 170: b1286-b1293.

22. Graat-Verboom L, Spruit MA, van den Borne BE, Smeenk FW, Martens EJ, et al. (2009) Correlates of osteoporosis in chronic obstructive pulmonary disease: An underestimated systemic component. Respir Med 103: 1143-1151.

23. Bolton CE, Cannings-John R, Edwards PH, lonescu AA, Evans WD, et al (2008) What community measurements can be used to predict bone disease in patients with COPD? Respir Med 102: 651-657.

24. Kjensli A, Falch JA, Ryg M, Blenk T, Armbrecht G, et al. (2009) High prevalence of vertebral deformities in COPD patients: relation to disease severity. Eur Respir J 33: 1018-1024.
25. Wouters EF (2005) Local and systemic inflammation in chronic obstructive pulmonary disease. Proc Am Thorac Soc 2: 26-33.

26. Yawn BP, Kaplan A (2008) Co-morbidities in people with COPD: a result of multiple diseases, or multiple manifestations of smoking and reactive inflammation? Prim Care Respir J 17: 199-205.

27. Cavanagh PR, Licata AA, Rice AJ (2005) Exercise and pharmacological countermeasures for bone loss during long-duration space flight. Gravit Space Biol Bull 18: 39-58.

28. Vrieze A, de Greef MH, Wijkstra PJ, Wempe JB (2007) Low bone mineral density in COPD patients related to worse lung function, low weight and decreased fat-free mass. Osteoporosis International 18: 1197-1202. 